\title{
Succession and interaction of surface and subsurface cyanobacterial blooms in oligotrophic/mesotrophic reservoirs: a case study in Miyun Reservoir
}

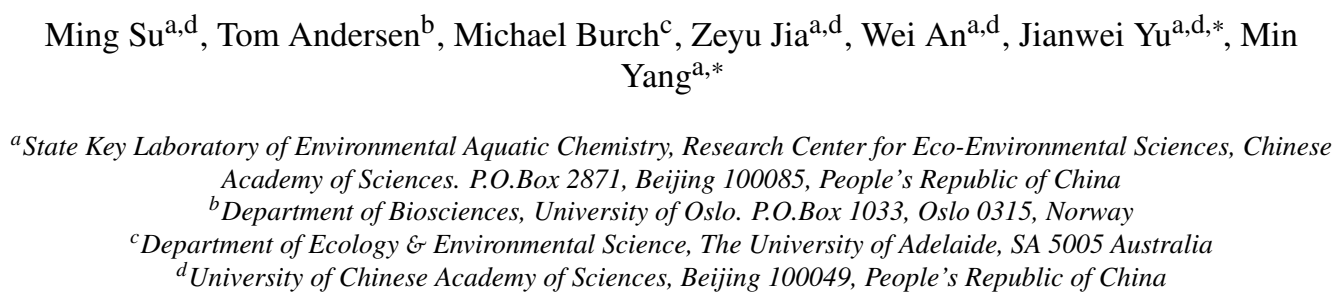

11 Abstract

Subsurface cyanobacterial blooms, are a significant source of odor problems in source water and have been recorded in many oligotrophic/mesotrophic drinking water reservoirs. In this study, we explored the key driving forces responsible for the succession between surface and subsurface cyanobacteria using ecological niche modelling based upon a case study in Miyun Reservoir, China. The results suggest a negative effect of water depth and surface light irradiance $\left(\mathrm{I}_{0}\right)$ on subsurface Planktothrix sp. growth (p-values $<0.001$ ), and a unimodal effect of surface water temperature $\left(\mathrm{T}_{0}\right)$ with the optimum at $23{ }^{\circ} \mathrm{C}$ (p-value $\left.<0.001\right)$. While the surface Microcystis spp. shows a strong positive relationship with temperature $\left(\mathrm{T}_{0} ; \mathrm{p}\right.$-value $\left.<0.001\right)$, and significant effects for the interaction between $\mathrm{T}_{0}$ and $\mathrm{I}_{0}$ (p- value $<0.01$ ). In addition, we identified the extent and type of interaction between subsurface and surface cyanobacteria and conclude that the high irradiance surface water combined with sufficient nutrients at the prebloom stage are key factors responsible for the preferential growth of surface cyanobacteria, while the gradual decline of the surface cyanobacteria in post-bloom stage is associate with nutrient reduction. This decline and loss of surface populations enhanced underwater irradiance and thus promoted the growth and allowed for succession of subsurface cyanobacteria in deeper layers where the nutrient supply was still adequate. Based upon this, the growth potentials for the subsurface and surface cyanobacteria are different under different environmental conditions: the subsurface cyanobacteria have greater growth potential than surface cyanobacteria in shallow oligotrophic and deep eutrophic reservoirs during median light irrigation seasons. 
Keywords: Generalized Additive Model, Ecological niche, Surface cyanobacteria, subsurface cyanobacteria, Source water, Taste and odor

\section{Introduction}

Cyanobacteria have developed advantages and strategies through evolution that allow them to flourish in aquatic environments, producing massive blooms, scums and mats (Huisman and Hulot, 2005). They also produce a diverse range of compounds that include tastes (Yang et al., 2008, Kehoe et al., 2015, Bai et al., 2017, Survey et al., 2017) and toxins (MacKintosh et al., 1990, Molica et al., 2005, Dittmann et al., 2013, Buratti et al., 2017), which degrade water quality. For example, globally the two most prominent cyanobacteria that produce striking surface blooms: Microcystis spp. produces microcystin toxins, and Dolichospermum spp. (formerly named as Anabaena spp.) can produce both anatoxin and saxitoxin neurotoxins in addition to the earthy smelly odor compound geosmin; and attract extensive concern and attention (Acun̆a et al., 2012, Liu et al., 2011, Chia et al., 2018). Surface-living cyanobacteria are able to regulate their buoyancy and therefore maintain a particular vertical position according to their needs, which can potentially provide an advantageous competitive strategy over non-buoyant phytoplankton (Mur et al., 1999, Yao et al., 2017, Wang et al., 2017). However, aesthetic and toxin-induced water quality problems are known to occur in some drinking water reservoirs, sometimes with low nutrient concentrations, and are not always associated with or and explained by the occurrence of surface bloom-forming cyanobacteria.

Example of cyanobacterial blooms that are not strongly buoyant such as the filamentous types Oscillatoria spp., Phormidium spp. etc., have been recorded in many reservoirs (AWWA, 2010, Dokulil and Teubner, 2012, Watson et al., 2016). These may have large biomass accumulations present either as mats on the sediment surface (Noffke et al., 2003) or are present as blooms deeper in the water column that produce high chlorophyll concentrations well below the epilimnion (Dokulil and Teubner, 2012). This behavior may seem paradoxical, since the surfaceliving cyanobacteria with access to sufficient irradiance would be expected to outcompete the

${ }^{*}$ Corresponding author(s). State Key Laboratory of Environmental Aquatic Chemistry, Research Center for EcoEnvironmental Sciences, Chinese Academy of Sciences P.O.Box 2871, Beijing 100085. Tel: +86 106284 9175; Fax: +861062923541.

Email addresses: jwyu@rcees.ac.cn (Jianwei Yu), yangmin@rcees.ac.cn (Min Yang) 
types with a preference for living in a subsurface zone (Davis et al., 2003). For water qual-

58 ity management, it is important to understand the combination of conditions or environmental changes that allow subsurface cyanobacteria to outcompete surface cyanobacteria.

The competitive exclusion principle (Hardin, 1960) has long been the tenet for predicting outcomes of competition between algal populations (Klausmeier and Litchman, 2001, Rothhaupt, 1996, Tilman et al., 1982). Huisman et al. (1999), have demonstrated that the species with "minimal resource requirements" should be the superior competitor. Dynamic competition models built around this principle and based upon differential equations usually work well for controlled conditions, and have been extensively used to explain competitive relationships among algal species in experimental laboratory systems (Huisman and Weissing, 1995, Huisman et al., 1999, Rothhaupt, 1996). However, with regard to the natural environment, the models are not necessarily applicable where the resources for their growth vary spatially and also seasonally. The application of mechanistic models in field studies can be challenging owing to the complex interplay between physical and chemical properties of the aquatic environment and the responsiveness of the individual species (Huisman and Hulot, 2005). By contrast ecological niche models utilize associations between environmental variables and known species' occurrence localities to define abiotic conditions within which populations can be maintained (Guisan and Thuiller, 2005), and have already been integrated into a broad variety of research disciplines (reviewed by Raxworthy et al. (2007)). The niche hypervolume, defines the multi-dimensional space of resources (e.g., light irradiance, nutrients, temperature, etc.) available to (and specifically used by) organisms (Hutchinson, 1957) is constrained by a multivariate species' response function of the habitat vector. McKane et al. (2002) successfully used resource-based niches to analyze the plant species diversity and dominance in arctic tundra.

In this investigation we attempt to extend the niche space to include time scales, and hence integrate all the spatial and seasonally dependent vectors into a unified niche space. Since the organisms response at each point in the niche is specified, it is possible to model interspecies competition by comparing response vectors of competing species at points of niche overlap (Wuenscher, 1969). In this study, the niche concept is employed to evaluate and determine the driving forces responsible for the seasonal succession between the surface and subsurface cyanobacteria , using ecological niche modeling (Generalized Additive Models, a non-parametric statistical method; (Hastie and Tibshirani, 1990)) in a major Chinese drinking water reservoir. This is 
novel and unique application of the niche concept model to achieve improved understanding of

the behavior of cyanobacteria for source water management.

Miyun Reservoir, the most important surface water resource for the city of Beijing, has been subject to major taste \& odor problems for several years due to the development of subsurfaceliving blooms of Planktothrix sp. (Su et al., 2015). Hereby we perform niche modeling by using the long-term monitoring data in Miyun Reservoir, to assess the seasonal dynamics of surface and subsurface cyanobacteria, and identify the environmental constraints responsible for their seasonal succession. This can be used for the development of possible strategies for the prevention of subsurface cyanobacteria based upon their ecological niche in various environment conditions.

\section{Methods}

\subsection{Study area and sampling strategy}

The Miyun Reservoir is situated in the northeastern part of Beijing, China $\left(40^{\circ} 30^{\prime} \mathrm{N}, 116^{\circ} 55^{\prime} \mathrm{E}\right.$, Figure A1). It was initially constructed for flood control, irrigation and fisheries, but is now the major water source for the city of Beijing. The reservoir encompasses a large area, with a total storage capacity of $437.5 \mathrm{GL}$ and a surface area of $188 \mathrm{~km}^{2}$, as well as a complex bathymetry classified as a mountain valley reservoir type ( $\mathrm{Su}$ et al., 2014). Miyun Reservoir's major natural replenishment is from the Bai and Chao Rivers that contribute mean flow of $111 \mathrm{GL} \mathrm{yr}^{-1}$ and $203 \mathrm{GL} \mathrm{yr}^{-1}$, respectively (data from Beijing Water Authority, 2010 to 2013). The main outflow is a channel in the South Region of the reservoir at $18 \mathrm{~m}$ depth, where water is removed via pumping stations to waterworks.

The water samples were collected during 2006 and 2012. No sample was collected during January and February owing to the security limitation during the ice-covered period. Samples were collected from eight sites (MY01, MY02 ... MY08) before 2008; more sample sites were involved and more samples were collected during September and October when the off-flavor problems occurred between 2009 to 2012. Water samples were collected using a kemmerer water sampler from three different depths; surface and middle water samples were collected at $0.5 \mathrm{~m}$ and $5 \mathrm{~m}$ (for shallow water areas) or $8 \mathrm{~m}$ (for deep water areas) depth. The bottom water samples were collected above the sediment floor or at a maximum depth of $15 \mathrm{~m}$. Nutrients, 
phytoplankton cell counting and online monitoring including Secchi depth, surface water temperature, water depth were simultaneously monitored except very limit amount of unsuccessful detections, which were removed during the model construction in later sections.

\subsection{Data collection and laboratory analysis}

Field measurements and water samples were collected in a program from Miyun Reservoir to collect data on water temperature, optical properties, nutrient concentrations and cyanobacterial numbers. Samples for nutrient analyses were first filtered through a $0.45 \mu \mathrm{m}$ filter and then subsampled and analyzed for each individual nutrient using continuous flow analyzer (CFA, Skalar San++, Netherlands), according to standard methods (APHA, A., 1998). Water transparency, expressed as Secchi depth (SD), was measured with a Secchi disk (diameter: $20 \mathrm{~cm}$, black and white). Water temperature was measured in situ with a multi-parameter probe (YSI-6600, USA). Light irradiance on each sampling date in Miyun Reservoir was extracted from China Meteorological Data Service Center (CMDC) (CMDSC, 2018) using the downwelling short wave radiation. Subsamples $(100 \mathrm{~mL})$ for cell enumeration were preserved with $5 \%$ Lugol's iodine (Sherr and Sherr, 1993). After static settlement over $48 \mathrm{~h}$, the resulting 10-fold pre-concentrated samples were kept in dark until cell counting. The algal cell density was determined using the Utermöhl technique with a Sedgewick-Rafter counting chamber under an upright microscope (Nikon Eclipse 50i) with phase contrast and bright field illumination (Hasle, 1978) using the self-developed cell coutning tool (CCT v1.4, China, http://suming.me/cc/publish.htm). The number of filamentous algal cells was calculated by dividing the measured filamentous length by the mean cell length. The number of cells in colony species such as Microcystis was estimated based upon colony volume and mean cell density. The colony volume was measured using builtin micrometer in CCD (couple-charged device) cameras' software (Olympus DP80, Japan)., and the mean cell density was estimated by measuring certain number of colonies and corresponding cell numbers accomplished by CCT v1.4 according to $\rho=\sum_{\mathrm{i}=1}^{\mathrm{n}}\left(\frac{\mathrm{N}_{\mathrm{i}}}{\mathrm{V}_{\mathrm{i}}}\right) / \mathrm{n} ; \rho$ : mean cell density, $\mathrm{N}_{\mathrm{i}}$ : cell number of the $i_{\text {th }}$ colony, $V_{i}$ : volume of the $i_{\text {th }}$ colony, $n$ : number of colonies. The detailed cell enumeration and identification has been described in Su et al. (2015).

\subsubsection{Statistics analysis}

Generalized Additive Models (GAMs) is a generalized linear model in which the linear predictor depends linearly on unknown smooth functions of some predictor variables, and interest 
focuses on inference about these smooth functions (Hastie and Tibshirani, 1990). Analysis using

GAMs was performed to evaluate the effects of the spatial and temporal patterns of environmental factors as well as the regression models for the biomass of surface and subsurface cyanobacteria. Variance inflation factor (VIF) quantifies the severity of multicollinearity in an ordinary least squares regression analysis. VIF analysis was used for evaluate the collinearity of involved environmental factors as the predictors. GAMs, VIF analysis, descriptive statistics and data visualization has been performed using mgcv, car, vegan and graph package in R 3.3.2 (Wood, 2006, 2011, Fox and Weisberg, 2011, Oksanen et al., 2014, R Core Team, 2016).

\subsection{Temporal-spatial pattern fit of environmental factors}

Most environmental factors are affected by both long-term trends and within-year variation; as shown in Eq. (1), GAMs were used to decompose the temporal variation into seasonal patterns and inter-annual trends.

$$
y=\beta_{0}+f_{\text {seasonal }}\left(x_{1}\right)+f_{\text {trend }}\left(x_{2}\right)+\varepsilon, \varepsilon \sim N\left(0, \sigma^{2} \Lambda\right)
$$

where $\beta_{0}$ is the intercept, $f_{\text {seasonal }}$ and $f_{\text {trend }}$ are smooth functions for the seasonal and trend features. Seasonal components were represented by cyclical splines (Adams, 1974) to avoid discontinuity between the beginning and the end of a year. The seasonal indicator, $\mathrm{x}_{1}$, is represented by the sampling week number, while the long-term trend indicator, $\mathrm{x}_{2}$, is the sampling date in units of decimal years.

GAMs were also used to represent spatial patterns in the complex bathymetry of Miyun Reservoir. The spatial patterns were represented with two-dimensional smoothers of horizontal and vertical position referring to the stations in Figure A1. Each of these sites have a depth $\left(\mathrm{z}_{\max }\right)$ and a spatial position, but the 2-dimesnional (x, y)-position is reduced to a 1-dimensional position along with the main water flow pattern from the west reservoir dam via the north shallow region (channel) to the south reservoir dam, formed by a transect line (see Figure A3a). The distances along this transect line for those sites represents the horizontal position variation, and the vertical water depth of those sites (see Figure A3b) presents the vertical water depth variation.

$$
y=\beta_{0}+f_{\text {horizontal }}\left(x_{3}\right)+f_{\text {vertical }}\left(x_{4}\right)+\varepsilon, \varepsilon \sim N\left(0, \sigma^{2} \Lambda\right)
$$


where $\mathrm{x}_{3}$ represents the horizontal transect distance and $\mathrm{x}_{4}$ the water depth $\left(\mathrm{z}_{\max }\right.$; vertical distance to the bottom at the sampling sites).

\subsection{Niche modeling}

\subsubsection{Response variables and predictors}

A general approach to niche modeling is to predict conditional abundance distribution by smooth functions of one or more predictors. Phytoplankton count data typically contains a high abundance of zeros (in our case, $44.8 \%$ for Planktothrix spp. and $26.1 \%$ for Microcystis sp.). Since the zeros are consequences of the natural spatio-temporal dynamics of the phytoplankton populations, it is important that this feature of the data be represented properly. Zero-inflated data cannot be analyzed by standard statistical distributions (e.g., log-normal, Poisson, etc.) because of the high proportion of zeros (Zuur et al., 2007). The Tweedie distribution with variance scaling parameter, $1<\mathrm{p}<2$, is especially appealing to model zero-inflated data, and has recently been used in range of fields including ecology studies (Candy, 2004, Shono, 2008, Tascheri et al., 2010, Arcuti et al., 2013) and rainfall prediction (Dunn, 2004). We used the variance inflation factor (VIF) analysis to quantify collinearity of the model predictors.

\subsubsection{GAM modeling}

Among the many different strategies developed for ecological niche modeling, we will here focus on generalized additive models (GAMs). In this study, GAMs were used to identify the environmental constraints on the abundances of Microcystis spp. and Planktothrix sp.. Models for our zero-inflated continuous responses are specified as follows:

$$
E\left(y_{i}\right)=\beta_{0}+\sum_{j=1}^{m} s_{j}\left(x_{i j}\right)=\eta\left(x_{i}\right)
$$

Where $E$ is the function linking the mean response $y_{i}$ to the additive predictor $\eta\left(x_{i}\right)$. Semiparametric smooth functions of observed covariates $s_{j}$ 's are specified as piecewise polynomial basis functions.

Interaction terms were represented by tensor product smoothers (te () terms), which are less sensitive to scaling differences between interacting predictors than other representations (Wood et al., 2013). We investigated the importance of the interaction effect by comparing models with and without an explicit tensor product interaction (ti()) term. Model selection was based on 
combining generalized cross-validation with a penalty-based method for model simplification (Marra and Wood, 2011).

\section{Results}

\subsection{Temporal-spatial patterns of environmental conditions}

The nutrient concentrations indicate that Miyun Reservoir is mesotrophic with a total dissolved nitrogen (total $\mathrm{N}, \mathrm{TN}$ ) concentration of $967 \pm 317 \mu \mathrm{g} \mathrm{L}^{-1}$ (mean \pm Variance, $\mathrm{N}=1447$ ), ammonia $\left(\mathrm{NH}_{4}\right)$ concentration of $250 \pm 142 \mu \mathrm{g} \mathrm{L}^{-1}(\mathrm{~N}=1447)$, total phosphorus (total $\left.\mathrm{P}, \mathrm{TP}\right)$ concentration of $14 \pm 11 \mu \mathrm{g} \mathrm{L}^{-1}(\mathrm{~N}=1447)$ and water transparency Secchi depth (SD) of $2.34 \pm 0.86 \mathrm{~m}$ ( $\mathrm{N}=1465)$. Most limnological parameters in the Miyun Reservoir showed significant temporal variation (Figure 1), but with "rugs" in January and February owing to unevenly distributed sampling dates over seasons. Judging from the seasonal splines, total $\mathrm{N}$, nitrate and nitrite concentration exhibited very similar seasonal fluctuation patterns, with highest concentrations in spring, and lowest concentrations during July and August (only TN splines is shown in Figure 2). Ammonia, whose utilization is energetically more favorable for phytoplankton, is typically consumed more quickly and thus shows a different seasonal pattern from other nitrogen species. In our study, concentrations decrease from March through June, then increase until the end of October before again decreasing. The water level, represented by $\mathrm{z}_{\max }$, shows strong seasonal fluctuations, but indicates a clear decreasing inter-annual trend during the investigated years, which could probably cause the ammonia increases and SD decreases.

[Figure 1 about here.]

The $95 \%$ predictive intervals suggesting $\mathrm{T}_{0}$ (surface water temperature) and $\mathrm{I}_{0}$ (light irradiance above water surface) do not vary by sampling sites, while $z_{\max }$ and other factors show non-negligible spatial variations, due to complex bathymetry and large surface area of Miyun Reservoir. Figure 2 shows that the nutrient concentrations and Secchi depth in September varies along with the geographical position (presented by transect distance) and water depth (present by $\mathrm{Z}_{\max }$ ), respectively. The results suggesting the area in the middle of the transect line (corresponding to the north reservoir region) shows different environmental conditions from the beginning to the end of the transect line (corresponding to west reservoir and south reservoir regions).

[Figure 2 about here.] 


\subsection{Distributions of Microcystis and Planktothrix}

In total 162 genera/species of cyanobacteria and eukaryotic algae were detected during the entire study (data not shown). Here we focus on Microcystis and Planktothrix, as they are the main nuisance genera in the Miyun Reservoir. The mean concentrations of Microcystis and Planktothrix over the four year study period were 1251 cells $\mathrm{mL}^{-1}$ and 224 cells $\mathrm{mL}^{-1}$, respectively, indicating a higher concentration of Microcystis than Planktothrix, although this does not take into account cell volume, which varies approximately 1.6-fold (Microcystis $48 \mu \mathrm{m} \mathrm{m}^{3}$; Planktothrix : $77 \mu \mathrm{m} \mathrm{m}^{3}$, data from Su et al. (2014)) between the two cyanobacteria. Both genera exhibited seasonal variations (Figure $1(\mathrm{n}-\mathrm{o})$ ). Microcystis had rapid growth in summer followed by a gradual decline in autumn. The concentration of Planktothrix remained low in spring and summer, while peak concentrations were generally observed in September and/or October and subsequently decreased during the following months. Vertical distributions of Microcystis and Planktothrix in the north shallow area (NSR, see Figure A1) during September (September 7 and September 23 in 2012, sampling time around 10:00-12:00 AM) are shown in further detail (Figure 3). The top $2 \mathrm{~m}$ contained greater concentrations (54\%) of Microcystis cells, while Microcystis cell number contributed only $6 \%$ in the layer of " $6-8 \mathrm{~m}$ ". In contrast to this, only $9 \%$ Planktothrix cells were found in top $2 \mathrm{~m}$ while cells in the lower layers ("2-4 m", "4-6 m" and "6-8 m") contributed a higher concentration of about approximately $24 \%, 41 \%$ and $26 \%$ respectively to the total cell number of Planktothrix in the water column, respectively.

[Figure 3 about here.]

\subsection{Predictive parameters of the Microcystis and Planktothrix}

Variance inflation factor (VIF) analysis (see Table A2), indicated that both nutrient sources (represented by ammonia, total $\mathrm{N}$ and total $\mathrm{P}$ ) and the physical environment (represented by Secchi depth, water depth, surface temperature and irradiance) could be considered candidate predictor variables.

[Table 1 about here.]

The model for Planktothrix indicates that four parameters $\left(\mathrm{NH}_{4}, \mathrm{z}_{\max }, \mathrm{I}_{0}\right.$ and $\left.\mathrm{T}_{0}\right)$ make statistically significant contributions in the prediction of Planktothrix cell density; this model explains 
in total $38.1 \%$ of the total deviance (Table 1 ). On the other hand, three parameters including $\mathrm{NH}_{4}, \mathrm{Z}_{\max }$ and $\mathrm{T}_{0}$ as well as the interaction between $\mathrm{I}_{0}$ and $\mathrm{T}_{0}$ are the major contributors to predicting Microcystis cell density. $51.0 \%$ of total deviance is explained by this model (Table 1). The fitted GAM models suggest minimal effect of total N, total P or SD on either Planktothrix (all p-values $>0.40$ ) or Microcystis (all p-values $>0.20$ ), as shown in Table 1. Subsequently, we have simplified the two GAMs by removing inefficient predictors, as shown in Eq. (4).

$$
\begin{aligned}
& \log \left(E\left[C_{\text {pla }}\right]\right)=\beta_{0}+s_{1}\left(N H_{4}\right)+s_{2}\left(z_{\text {max }}\right)+s_{3}\left(T_{0}\right)+s_{4}\left(I_{0}\right)+t i\left(I_{0}, T_{0}\right) \\
& \log \left(E\left[C_{\text {mic }}\right]\right)=\beta_{0}+s_{1}\left(N H_{4}\right)+s_{2}\left(z_{\text {max }}\right)+s_{3}\left(T_{0}\right)+s_{4}\left(I_{0}\right)+t i\left(I_{0}, T_{0}\right)
\end{aligned}
$$

where $C_{p l a}$ and $C_{m i c}$ denote the cell density distributions of Planktothrix and Microcystis. Cell densities are assumed to follow a Tweedie distribution with a logarithmic link function, such that the logarithm of the expectation (The $E[]$ operator) is a linear combination of smoothers for ammonia, water depth, surface temperature and irradiance.

\subsection{Effects of environmental factors on Planktothrix}

The updated GAMs for Planktothrix (Eq. 4a) have a lower akaike information criterion (AIC) value, and can also explain a higher percentage of the total deviance (39.4\%) compared to the original one, suggesting that the simplified model performs better. According to the results of the updated model (Figure 4-top), $\mathrm{z}_{\max }$ has a negative effect on the growth of Planktothrix (p-value $<0.001)$. There was also very strong evidence showing a unimodal effect of surface temperature on Planktothrix, with the optimum around at $23^{\circ} \mathrm{C}$ (p-value $<0.001$ ), and a negative effect of surface light irradiance ( $\mathrm{p}$-value $<0.001)$.

[Figure 4 about here.]

\subsection{Effects of environmental factors on Microcystis}

As shown in Figure 4 (bottom), the updated model for Microcystis shows a strong positive relationship with surface water temperature $(\mathrm{p}$-value $<0.001)$ and it primarily occurred under low-nutrient conditions (ammonia: $20 \mu \mathrm{g} \mathrm{L}^{-1}$ to $200 \mu \mathrm{g} \mathrm{L}^{-1}$ (p-value $<0.01$ ). Microcystis tended to grow more in the north shallow region ( $6 \mathrm{~m}$ to $15 \mathrm{~m}$ ) than the deep regions ( $15 \mathrm{~m}$ to $30 \mathrm{~m}$ ) in the years in this study. Data also indicated that Microcystis showed lower cell density at water 
depths less than $6 \mathrm{~m}$, however this is mainly associated with samples collected in littoral area in September when Microcystis tended to collapse. There was no effect of surface irradiance alone on Microcystis, however there was a strong effect for the interaction between surface water temperature and irradiance ( $\mathrm{p}$-value $<0.01)$.

\subsection{Ecological niche analysis with predictive parameters}

The GAM models suggest that the four environmental factors, ammonia, water depth, surface irradiance and water temperature, are important predictors for cell densities of both Planktothrix and Microcystis. We have developed contour maps for the GAMs to illustrate the temporal and spatial interactive effects of the environmental factors (Figure 5 and 6). Amongst these factors irradiance and surface water temperature show strong seasonal fluctuations that do not vary with spatial location, water depth varies with location as expected, and ammonia shows both seasonal fluctuation and spatial variation. Amongst these variables, irradiance is a lead driver which is followed by surface water temperature as a lag; water depth is strongly determined by operational requirements; whereas $\mathrm{NH}_{4}$ will be seasonally influenced by both inflows and a biogeochemical response to seasonal drivers (irradiance and water temperature).

As a consequence niche analysis was performed along with the seasonal trajectory (combinations of two factors among $\mathrm{NH}_{4}, \mathrm{~T}_{0}$ and $\mathrm{I}_{0}$ ) and spatial trajectory (combination of $\mathrm{NH}_{4}$ and $\mathrm{Z}_{\max }$ ) of these factors in the Miyun Reservoir, and this is shown in Figure 5 and 6, respectively.

In terms of seasonal trajectory Planktothrix and Microcystis exhibit different seasonal patterns in all bi-dimensional environmental niche spaces. Microcystis has a preferred growing season and blooms are observed in July and August while Planktothrix is generally absent during this period; Planktothrix then increases towards the end of August and reaches a peak in September or early October, as Microcystis concentrations decline. In the $\mathrm{I}_{0} \times \mathrm{T}_{0}$ plane, the seasonal trajectory of these growth driving variables has an elliptic orbit in the anti-clockwise direction. This is associated with the time required for water temperatures to increase over the spring and summer. Planktothrix populations develop associated with modest surface temperatures and irradiance conditions (Figure 5 (a)), while Microcystis mainly occur in high temperature conditions

(Figure $5(\mathrm{~d})$ ). In the $\mathrm{NH}_{4} \times \mathrm{T}_{0}$ plane (Figure $5(\mathrm{~b}, \mathrm{e})$ ), both genera appeared to be more sensitive to water temperature. The two genera exhibit reciprocal patterns in the $\mathrm{NH}_{4} \times \mathrm{I}_{0}$ plane (Figure 5 (c, f)) with Planktothrix mainly present in lower irradiance conditions and Microcystis more 
abundant at high light irradiance. This pattern is also reflected in the overall depth distribution of the two genera (Figure 3).

[Figure 5 about here.]

The spatial trajectory of the niche space of both Planktothrix and Microcystis on the $\mathrm{NH}_{4} \times$ $\mathrm{Z}_{\max }$ plane indicate that ammonia concentration and $\mathrm{z}_{\max }$ vary in different regions of the reservoir with a controlling effect upon the spatial distribution of Planktothrix and Microcystis. (Figure 6). The greatest concentrations of both genera are generally observed in the north and northeast shallow regions of Miyun Reservoir. Planktothrix is primarily found in the littoral areas $\left(\mathrm{z}_{\max }<\right.$ $5 \mathrm{~m}$ ) of the shallow regions, whereas Microcystis is found in low concentrations in littoral areas. Overall Microcystis shows higher concentrations in shallow north region compared to the deep regions in the west and south.

[Figure 6 about here.]

\section{Discussion}

The Microcystis seasonal patterns show growth as early as April and it becomes the dominant species by July (data not shown). Planktothrix is rarely observed before August and its growth is greatest at a time that Microcystis is declining. Our findings indicate that ammonia, water depth, surface water temperature and irradiance are the essential predictors of Microcystis and Planktothrix, but they act in different ways. For example, elevated ammonia can be regarded as being both a cause and an effect of a bloom. Microcystis is dependent upon surface water temperature and water depth while Planktothrix is dependent upon these factors as well, but also dependent upon surface light irradiance. The seasonal cycles of inorganic nutrients are also correlated with the annual temperature cycle. It is possible that there is a confounding effect of water temperature with other seasonal signals. We nevertheless find that light irradiance and temperature are robust and parsimonious predictors of the seasonal cycles of Planktothrix and Microcystis in the Miyun Reservoir. The biomass of Microcystis is mainly limited by low concentrations of inorganic nutrient resources (mainly P) that are depleted in late August (Figure 4 (a-d)). On the other hand, the growth of Planktothrix density does not demonstrate this relationship, and is mainly influenced by the combination of preferred water depth and irradiance. The Planktothrix growth 
season commences in September as Microcystis begins to decline from the surface layer. What we find is that Planktothrix shows a negative relationship with water depth, which is consistent of ecotypes that can have distinct vertical and seasonal distribution in a Norwegian Lake (Rohrlack et al., 2008).

Vertical distribution of Microcystis in the water column has been widely studied over the last 40 years (Brookes and Ganf, 2001, Wu and Kong, 2009). The vertical movement of Microcystis is mainly driven by vertical mixing process of the water column in conjunction with buoyancy adjustment. Morphological features have been used to explain the habitat of different genera/species (Su et al., 2014); Microcystis tends to have greater concentrations at the top of the water column where light irradiance is high but where nutrient concentrations can be severely depleted (Liu et al., 2015). Microcystis cells also have both a small cross-sectional area $\left(22.8 \mu \mathrm{m}^{2}\right.$, (Su et al., 2014)) and a high specific surface area $1.42 \mu \mathrm{m}^{-1}$ that are associated with low light-harvesting potential and high nutrient uptake affinity. Compared to Microcystis, Planktothrix cells however have a higher cross-sectional area $\left(172 \mu \mathrm{m}^{2}\right)$ and lower specific surface area $\left(1.06 \mu \mathrm{m}^{-1}\right)$ which results in higher light-harvesting potential and lower nutrient-utilization capability. This allows for better adaptation by Planktothrix to lower irradiance in deeper layers. This conclusion is consistent with another case study for Planktothrix rubescens in Lake Zürich (Van den Wyngaert et al., 2011). Besides differences in morphological features, high temperature has been regarded as a key factor predicting Microcystis blooms. Also in relation to temperature preferences, Planktothrix rubescens appeared to be much more competitive than Planktothrix agardhii in $15^{\circ} \mathrm{C}$, while Planktothrix agardhii was more competitive at $25^{\circ} \mathrm{C}$ in competition experiments (Oberhaus et al., 2007).

Microcystis and Planktothrix blooms have been frequently recorded and the niche of each genera have also been widely analyzed (Walsby and Schanz, 2002, Oberhaus et al., 2007, Davis et al., 2009, Cuypers et al., 2011, Van den Wyngaert et al., 2011, Gallina et al., 2017, Chaffin et al., 2018); however, the interactions and resources competition including light irradiance and nutrient between two genera have rarely been discussed. Our findings suggest that surface irradiance is the main predictor determining the outcomes of competition between surface and subsurface cyanobacteria. In Table 2, we speculated in more general terms the niche model predictions in relation to seasonal conditions and lake properties. Density stratification will typically be weaker in shallow water bodies, resulting in strong vertical mixing and high nutrient supply 
fluxes from the sediments. Surface-living cyanobacteria like Microcystis, which are well adapted to high light irradiance and nutrient conditions, will have frequent and serious blooms under such conditions, and a prominent example of this is in hyper-eutrophic Lake Taihu in Jiangsu, China (Qin et al., 2010). While the subsurface cyanobacteria have a higher growth potential under low light irradiance conditions, lower growth may occur in eutrophic water bodies because of competition from surface blooms of Microcystis, which may reduce the penetration of subsurface irradiance. This is consistent with findings of great Planktothrix abundance in the shallow areas of the Miyun Reservoir (Su et al., 2017). Light preferences and competitive access by two Planktothrix species was also confirmed in an earlier laboratory study (Oberhaus et al., 2007). This study found that pigmentation of these strains was of primary importance in determining the outcomes of the competition experiments under low irradiance. We found that subsurface growth Planktothrix is likely to be reduced or be limited by shading by surface dwelling Microcystis blooms under high light conditions in summer in Miyun Reservoir. The Planktothrix population has difficulty growing until subsurface light irradiance is able to increase (typically starting in September) associated with the collapse of Microcystis. Besides, cyanobacteria possess a buoyancy regulation mechanism to influence their vertical position along the water column (Medrano et al., 2013). Serizawa et al. (2010) compared the buoyancy regulation mechanism in surface scum cyanobacteria and filamentous cyanobacteria based on a shape factor referring to as the coefficient of form resistance (Reynolds et al., 1987), addressing that the buoyancy regulation of filamentous cyanobacteria was weakened owing to their slender shape compare with Microcystis. This provide another advantag of the surface Microcystis over the subsurface cyanobacteria.

These observations agree with the concept of the "critical light irradiance" required to support and sustain competitive growth of different phytoplankton species under light-limited conditions proposed by Huisman and Weissing (1994). They proposed a model which is applicable to competition for light under well-mixed water conditions, where each algal or cyanobacterial species has a different "critical light irradiance" which must be exceeded for the species to grow and increase in population size (Huisman and Hulot, 2005). In the case of Microcystis in Miyun Reservoir it has adequate light above this irradiance during summer growth under stratified conditions and continues to shade the water column and prevents Planktothrix from receiving its "critical light irradiance" threshold to initiate and sustain growth, until nutrient depletion causes Microcystis to decline. 
This interaction with nutrient availability in deeper water is also critically important, In the deeper regions of the reservoir, the water column will typically be stratified during the warm summer months. This will reduce or eliminate vertical mixing which leads to reduction in supply from sediments and results in nutrient limitation for the over-buoyant surface dwelling Microcystis populations. This mechanism represents part of the explanation for the decline of Microcystis in Miyun Reservoir and succession to sub-surface cyanobacteria. Thus, nutrients responsible for the succession of surface and subsurface cyanobacteria become more important in deep water vs shallow water.

[Table 2 about here.]

\section{Conclusion}

In this study, the main mechanisms driving the of the succession and interaction between the surface and subsurface cyanobacteria in a major Chinese Reservoir have been proposed based upon the ecological niche concept derived from the GAM modeling. Underwater light irradiance, controlled by both surface light irradiance and water column transparency, is regarded as a critical factor to control the growth of subsurface cyanobacteria in this reservoir, and might be perhaps also applied to other shallow and oligotrophic/mesotrophic waters, while nutrients may play a more important role in deeper waters with eutrophic conditions. The study has also demonstrated the role of competitive interaction for light with surface bloom forming species and sub-surface types that grow at depth, with summer surface blooms of Microcystis causing shading that causes a delay to the onset of growth of sub-surface types until summer blooms decline.

\section{Acknowledgement}

We would like to thank Dr. Marcia Kyle for linguistic improvements and English corrections. This work was financially supported by the National Natural Science Foundation of China (51508549), the Funds for Major Science and Technology Program for Water Pollution Control and Treatment (2015ZX07406001, 2017ZX07108002). 


\section{References}

Acun̆a, S., Baxa, D., Teh, S., 2012. Sublethal dietary effects of microcystin producing Microcystis on threadfin shad, dorosoma petenense. Toxicon 60 (6), 1191-1202. doi: http://dx.doi.org/10.1016/j.toxicon.2012.08. 004

Adams, J., 1974. Cubic spline curve fitting with controlled end conditions. Computer-Aided Design 6 (1), 2 - 9. doi: http://dx.doi.org/10.1016/0010-4485(74)90132-8

APHA, A., 1998. Wef, standard methods for the examination of water and wastewater 20th edition.

Arcuti, S., Calculli, C., Pollice, A., D’Onghia, G., Maiorano, P., Tursi, A., 2013. Spatio-temporal modelling of zeroinflated deep-sea shrimp data by tweedie generalized additive. Statistica 73 (1), 87-101. doi: http://dx.doi.o rg/10.6092/issn.1973-2201/3987

AWWA, A. W. W. A., 2010. Algae: Source to Treatment. American Water Works Association.

Bai, X., Zhang, T., Wang, C., Zong, D., Li, H., Yang, Z., Jan 2017. Occurrence and distribution of taste and odor compounds in subtropical water supply reservoirs and their fates in water treatment plants. Environmental Science and Pollution Research 24 (3), 2904-2913. doi: http: //dx . doi .org/10.1007/s11356-016-7966-5

Brookes, J. D., Ganf, G. G., 2001. Variations in the buoyancy response of Microcystis aeruginosa to nitrogen, phosphorus and light. Journal of Plankton Research 23 (12), 1399-1411. doi: http://dx.doi.org/10.1093/plankt/23. 12.1399

Buratti, F. M., Manganelli, M., Vichi, S., Stefanelli, M., Scardala, S., Testai, E., Funari, E., Mar 2017. Cyanotoxins: producing organisms, occurrence, toxicity, mechanism of action and human health toxicological risk evaluation. Archives of Toxicology 91 (3), 1049-1130. doi: http://dx.doi.org/10.1007/s00204-016-1913-6

Candy, S., 2004. Modelling catch and effort data using generalised linear models, the tweedie distribution, random vessel effects and random stratum-by-year effects. Ccamlr Science 11, 59-80.

Chaffin, J. D., Davis, T. W., Smith, D. J., Baer, M. M., Dick, G. J., 2018. Interactions between nitrogen form, loading rate, and light intensity on Microcystis and Planktothrix growth and microcystin production. Harmful Algae 73, $84-$ 97. doi: http://dx.doi.org/10.1016/j.hal.2018.02.001

Chia, M. A., Jankowiak, J. G., Kramer, B. J., Goleski, J. A., Huang, I.-S., Zimba, P. V., do Carmo Bittencourt-Oliveira, M., Gobler, C. J., 2018. Succession and toxicity of Microcystis and Anabaena (Dolichospermum) blooms are controlled by nutrient-dependent allelopathic interactions. Harmful Algae 74, 67 - 77. doi: http://dx.doi .org/10. $1016 / j$.hal . 2018.03.002

CMDSC, C. M. D. S. C., 2018. Data set of daily radiation in china. https://data.cma.cn/en. URL: https: //data.cma.cn/en

Cuypers, Y., Vincon-Leite, B., Groleau, A., Tassin, B., Humbert, J.-F., Apr. 2011. Impact of internal waves on the spatial distribution of Planktothrix rubescens (cyanobacteria) in an alpine lake. ISME J 5 (4), 580-589. URL: http: //dx.doi.org/10.1038/ismej.2010.154

Davis, P., Dent, M., Parker, J., Reynolds, C., Walsby, A., 2003. The annual cycle of growth rate and biomass change in Planktothrix spp. in Blelham Tarn, English Lake District. Freshwater Biology 48 (5), 852-867. doi: http://dx.d oi.org/10.1046/j.1365-2427.2003.01055.x

Davis, T. W., Berry, D. L., Boyer, G. L., Gobler, C. J., 2009. The effects of temperature and nutrients on the growth and 
dynamics of toxic and non-toxic strains of Microcystis during cyanobacteria blooms. Harmful Algae 8 (5), 715 - 725 , this issue contains the special section on Strains. doi: http://dx.doi.org/10.1016/j.hal.2009.02.004

Dittmann, E., Fewer, D. P., Neilan, B. A., 2013. Cyanobacterial toxins: biosynthetic routes and evolutionary roots. FEMS Microbiology Reviews 37 (1), 23-43. doi: http://dx.doi.org/10.1111/j.1574-6976.2012.12000.x

Dokulil, M., Teubner, K., 2012. Deep living Planktothrix rubescens modulated by environmental constraints and climate forcing. Hydrobiologia 698 (1), 29-46. doi: http: //dx.doi.org/10.1007/s10750-012-1020-5

Dunn, P. K., 2004. Occurrence and quantity of precipitation can be modelled simultaneously. International Journal of Climatology 24 (10), 1231-1239.

Fox, J., Weisberg, S., 2011. An R Companion to Applied Regression, 2nd Edition. Sage, Thousand Oaks CA. URL: http://socserv.socsci.mcmaster.ca/jfox/Books/Companion

Gallina, N., Beniston, M., Jacquet, S., Apr 2017. Estimating future cyanobacterial occurrence and importance in lakes: a case study with Planktothrix rubescens in Lake Geneva. Aquatic Sciences 79 (2), 249-263. doi: http://dx.doi .org/10.1007/s00027-016-0494-z

Guisan, A., Thuiller, W., 2005. Predicting species distribution: offering more than simple habitat models. Ecology Letters 8 (9), 993-1009. doi: http://dx.doi.org/10.1111/j.1461-0248.2005.00792.x

Hardin, G., 1960. The competitive exclusion principle. Science 131 (3409), 1292-1297. doi: http://dx.doi.org /10.1126/science.131.3409.1292

Hasle, G. R., 1978. A. Sournia (ed) phytoplankton manual. Unesco (Paris).

Hastie, T. J., Tibshirani, R. J., 1990. Generalized additive models. Vol. 43. CRC Press.

Huisman, J., Hulot, F., 2005. Population dynamics of harmful cyanobacteria. In: Huisman, J., Matthijs, H., Visser, P. (Eds.), Harmful Cyanobacteria. Vol. 3 of Aquatic Ecology Series. Springer Netherlands, pp. 143-176. doi: http: //dx.doi.org/10.1007/1-4020-3022-3_7

Huisman, J., van Oostveen, P., Weissing, F. J., 1999. Species dynamics in phytoplankton blooms: incomplete mixing and competition for light. The American Naturalist 154 (1), 46-68.

Huisman, J., Weissing, F. J., 1994. Light-limited growth and competition for light in well-mixed aquatic environments: an elementary model. Ecology, 507-520.

Huisman, J., Weissing, F. J., 1995. Competition for nutrients and light in a mixed water column - a theoretical-analysis. American Naturalist 146 (4), 536-564. doi: http://dx.doi.org/10.1086/285814

Hutchinson, G. E., 1957. Cold spring harbor symposium on quantitative biology. Concluding remarks 22, $415-427$.

Kehoe, M. J., Chun, K. P., Baulch, H. M., 2015. Who smells? forecasting taste and odor in a drinking water reservoir. Environmental Science \& Technology 49 (18), 10984-10992, pMID: 26266956. doi: http://dx.doi.org/10. 1021 /acs.est. 5 b00979

Klausmeier, C. A., Litchman, E., 2001. Algal games: The vertical distribution of phytoplankton in poorly mixed water columns. Limnology and Oceanography 46 (8), 1998-2007.

Liu, L., Yang, J., Yu, Z., Wilkinson, D. M., 2015. The biogeography of abundant and rare bacterioplankton in the lakes and reservoirs of China. The ISME Journal 9 (9), 2068-2077, original Article. doi: http://dx.doi.org/10. 1038/ismej.2015.29

Liu, X., Lu, X., Chen, Y., 2011. The effects of temperature and nutrient ratios on Microcystis blooms in Lake Taihu, China: An 11-year investigation. Harmful Algae 10 (3), 337-343. doi: http://dx.doi.org/10.1016/j.hal. 
2010.12 .002

MacKintosh, C., Beattie, K. A., Klumpp, S., Cohen, P., Codd, G. A., 1990. Cyanobacterial microcystin-LR is a potent and specific inhibitor of protein phosphatases 1 and 2a from both mammals and higher plants. FEBS Letters 264 (2), 187 - 192. doi: http://dx.doi.org/http://dx.doi.org/10.1016/0014-5793(90)80245-E

Marra, G., Wood, S. N., 2011. Practical variable selection for generalized additive models. Computational Statistics \& Data Analysis 55 (7), 2372 - 2387. doi: http://dx.doi.org/10.1016/j.csda.2011.02.004

McKane, R. B., Johnson, L. C., Shaver, G. R., Nadelhoffer, K. J., Rastetter, E. B., Fry, B., Giblin, A. E., Kielland, K., Kwiatkowski, B. L., Laundre, J. A., Murray, G., Jan 2002. Resource-based niches provide a basis for plant species diversity and dominance in arctic tundra. Nature 415 (6867), 68-71. doi: http: //dx . doi .org/10.1038/ $415068 \mathrm{a}$

Medrano, E. A., Uittenbogaard, R., Pires, L. D., van de Wiel, B., Clercx, H., 2013. Coupling hydrodynamics and buoyancy regulation in Microcystis aeruginosa for its vertical distribution in lakes. Ecological Modelling $248,41-56$ doi: http://dx.doi.org/10.1016/j.ecolmodel.2012.08.029

Molica, R. J., Oliveira, E. J., Carvalho, P. V., Costa, A. N., Cunha, M. C., Melo, G. L., Azevedo, S. M., 2005. Occurrence of saxitoxins and an anatoxin-a(s)-like anticholinesterase in a brazilian drinking water supply. Harmful Algae 4 (4), 743 - 753. doi: http://dx.doi.org/http://dx.doi.org/10.1016/j.hal.2004.11.001

Mur, L. R., Skulberg, O. M., Utkilen, H., 1999. Cyanobacteria in the environment. Biochimica et Biophysica Acta.

Noffke, N., Gerdes, G., Klenke, T., 2003. Benthic cyanobacteria and their influence on the sedimentary dynamics of peritidal depositional systems (siliciclastic, evaporitic salty, and evaporitic carbonatic). Earth-Science Reviews 62 (12), 163 - 176. doi: http://dx.doi.org/10.1016/S0012-8252(02)00158-7

Oberhaus, L., Briand, J. F., Leboulanger, C., Jacquet, S., Humbert, J. F., 2007. Comparative effects of the quality and quantity of light and temperature on the growth of Planktothrix agardhii and P. rubescens. Journal of Phycology 43 (6), 1191-1199. doi: http://dx.doi.org/10.1111/j.1529-8817.2007.00414.x

Oksanen, J., Blanchet, F. G., Kindt, R., Legendre, P., Minchin, P. R., O’Hara, R. B., Simpson, G. L., Solymos, P., Stevens, M. H. H., Wagner, H., 2014. vegan: Community Ecology Package. R package version 2.2-0. URL: http: //CRAN.R-project.org/package=vegan

Qin, B., Zhu, G., Gao, G., Zhang, Y., Li, W., Paerl, H., Carmichael, W., 2010. A drinking water crisis in Lake Taihu, China: Linkage to climatic variability and lake management. Environmental Management 45, 105-112. doi: http: //dx.doi.org/10.1007/s00267-009-9393-6

R Core Team, 2016. R: A Language and Environment for Statistical Computing. R Foundation for Statistical Computing, Vienna, Austria. URL: https://www.R-project.org/

Raxworthy, C. J., Ingram, C. M., Rabibisoa, N., Pearson, R. G., Weins, J., 2007. Applications of ecological niche modeling for species delimitation: A review and empirical evaluation using day geckos (phelsuma) from madagascar. Systematic Biology 56 (6), 907-923. doi: http://dx.doi.org/10.1080/10635150701775111

Reynolds, C. S., Oliver, R. L., Walsby, A. E., 1987. Cyanobacterial dominance: The role of buoyancy regulation in dynamic lake environments. New Zealand Journal of Marine and Freshwater Research 21 (3), 379-390. doi: http: //dx.doi.org/10.1080/00288330.1987.9516234

Rohrlack, T., Edvardsen, B., Skulberg, R., Halstvedt, C. B., Utkilen, H. C., Ptacnik, R., Skulberg, O. M., JUL 2008. Oligopeptide chemotypes of the toxic freshwater cyanobacterium Planktothrix can form subpopulations with dissim- 
ilar ecological traits. Limnology and Oceanography 53 (4), 1279-1293. doi: http://dx.doi .org/\{10.4319/10 $.2008 .53 .4 .1279\}$

Rothhaupt, K. O., 1996. Laboratorary experiments with a mixotrophic chrysophyte and obligately phagotrophic and photographic competitors. Ecology 77 (3), pp. 716-724. URL: http://www.jstor.org/stable/2265496

Serizawa, H., Amemiya, T., Itoh, K., 2010. Effects of buoyancy, transparency and zooplankton feeding on surface maxima and deep maxima: Comprehensive mathematical model for vertical distribution in cyanobacterial biomass. Ecological Modelling 221 (17), 2028 - 2037. doi: http://dx.doi.org/10.1016/j . ecolmodel .2010.05.009

Sherr, E. B., Sherr, B. F., 1993. Preservation and storage of samples for enumeration of heterotrophic protists. Handbook of methods in aquatic microbial ecology. Lewis Publishers, Boca Raton, 207-212.

Shono, H., 2008. Application of the tweedie distribution to zero-catch data in CPUE analysis. Fisheries Research 93 (12), 154 - 162. doi: http://dx.doi.org/10.1016/j.fishres.2008.03.006

Su, M., An, W., Yu, J., Pan, S., Yang, M., 2014. Importance of underwater light field in selecting phytoplankton morphology in a eutrophic reservoir. Hydrobiologia 724 (1), 203-216. doi: http://dx.doi.org/10.1007/ s10750-013-1734-z

Su, M., Jia, D., Yu, J., Vogt, R. D., Wang, J., An, W., Yang, M., 2017. Reducing production of taste and odor by deepliving cyanobacteria in drinking water reservoirs by regulation of water level. Science of The Total Environment 574, 1477 - 1483. doi: http://dx.doi.org/10.1016/j.scitotenv.2016.08.134

Su, M., Yu, J., Zhang, J., Chen, H., An, W., Vogt, R. D., Andersen, T., Jia, D., Wang, J., Yang, M., 2015. MIBproducing cyanobacteria (Planktothrix sp.) in a drinking water reservoir: Distribution and odor producing potential. Water Research 68, 444-453. doi: http://dx.doi.org/10.1016/j.watres. 2014.09.038

Survey, U. S. G., Graham, J. L., Foster, G. M., Williams, T. J., Kramer, A. R., Harris, T. D., 2017. Occurrence of cyanobacteria, microcystin, and taste-and-odor compounds in Cheney Reservoir, Kansas, 2001-16. Tech. rep., Reston, VA. doi: http://dx.doi.org/10.3133/sir20175016

Tascheri, R., Saavedra-Nievas, J., Roa-Ureta, R., 2010. Statistical models to standardize catch rates in the multi-species trawl fishery for Patagonian grenadier (Macruronus magellanicus) off Southern Chile. Fisheries Research 105 (3), 200 - 214. doi: http://dx.doi.org/10.1016/j.fishres.2010.05.010

Tilman, D., Kilham, S. S., Kilham, P., 1982. Phytoplankton community ecology: the role of limiting nutrients. Annual Review of Ecology and Systematics 13, 349-372. doi: http://dx.doi.org/10.1146/annurev.es.13. 110182.002025

Van den Wyngaert, S., Salcher, M. M., Pernthaler, J., Zeder, M., Posch, T., 2011. Quantitative dominance of seasonally persistent filamentous cyanobacteria (Planktothrix rubescens) in the microbial assemblages of a temperate lake. Limnology and Oceanography 56 (1), 97-109.

Walsby, A. E., Schanz, F., 2002. Light-dependent growth rate determines changes in the population of Planktothrix rubescens over the annual cycle in lake Zürich, Switzerland. New Phytologist 154 (3), 671-687. doi: http://dx .doi.org/10.1046/j.1469-8137.2002.00401.x

Wang, C., Feng, T., Wang, P., Hou, J., Qian, J., 2017. Understanding the transport feature of bloom-forming Microcystis in a large shallow lake: A new combined hydrodynamic and spatially explicit agent-based modelling approach. Ecological Modelling 343, 25 - 38. doi: http://dx. doi .org/10.1016/j . ecolmodel.2016.10.017

Watson, S. B., Monis, P., Baker, P., Giglio, S., 2016. Biochemistry and genetics of taste- and odor-producing cyanobac- 
teria. Harmful Algae 54, 112 - 127. doi: http://dx.doi.org/10.1016/j.hal.2015.11.008

Wood, S., 2006. Generalized Additive Models: An Introduction with R. Chapman and Hall/CRC.

Wood, S. N., 2011. Fast stable restricted maximum likelihood and marginal likelihood estimation of semiparametric generalized linear models. Journal of the Royal Statistical Society (B) 73 (1), 3-36.

Wood, S. N., Scheipl, F., Faraway, J. J., 2013. Straightforward intermediate rank tensor product smoothing in mixed models. Statistics and Computing 23 (3), 341-360. doi: http://dx.doi .org/10.1007/s11222-012-9314-z

Wu, X., Kong, F., 2009. Effects of light and wind speed on the vertical distribution of Microcystis aeruginosa colonies of different sizes during a summer bloom. International Review of Hydrobiology 94 (3), 258-266. doi: http: //dx.doi.org/10.1002/iroh.200811141

Wuenscher, J. E., 1969. Niche specification and competition modeling. Journal of Theoretical Biology 25 (3), 436 - 443. doi: http://dx.doi.org/10.1016/S0022-5193(69)80031-7

Yang, M., Yu, J., Li, Z., Guo, Z., Burch, M., Lin, T.-F., 2008. Taihu Lake not to blame for Wuxi's Woes. Science 319 (5860), 158. doi: http://dx.doi.org/10.1126/science.319.5860.158a

Yao, B., Liu, Q., Gao, Y., Cao, Z., Nov 2017. Characterizing vertical migration of Microcystis aeruginosa and conditions for algal bloom development based on a light-driven migration model. Ecological Research 32 (6), 961-969. doi: http://dx.doi.org/10.1007/s11284-017-1505-9

Zuur, A. F., Ieno, E. N., Smith, G. M., 2007. Analysing ecological data. Vol. 680. Springer New York. 

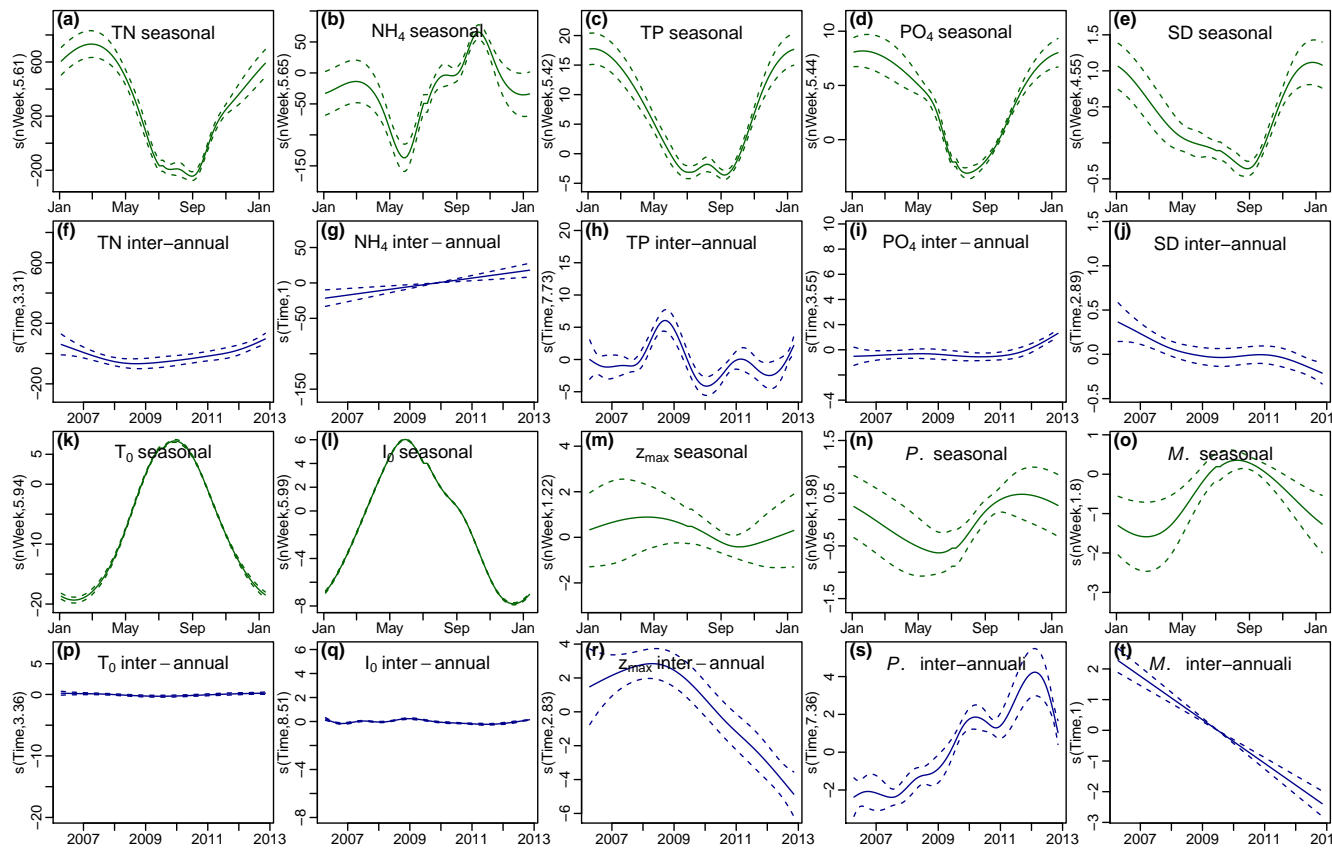

Figure 1: The seasonal patterns (a-e, k-o; Annual Mean over 7 years) and inter-annual trend (f-j, p-t; 2007-2013) of major environmental variables influencing the ecology and population development of Microcystis (o,t) and Planktothrix $(\mathrm{n}, \mathrm{s})$ in Miyun Reservoir. Y-axis represents GAM modelled results corresponding to the seasonal and trend term of each parameter. Abbreviations - TN, total nitrogen; $\mathrm{NH}_{4}$ Ammonia; $\mathrm{TP}$, total phosphorus; $\mathrm{PO}_{4}$, Soluble Phosphorus; SD, secchi disk depth; $\mathrm{T}_{0}$, surface water temperature; $\mathrm{I}_{0}$, Surface light irradiance; $\mathrm{z}_{\max }$, maximum depth; $\mathrm{P}$, Planktothrix spp.; M, Microcystis spp.. 

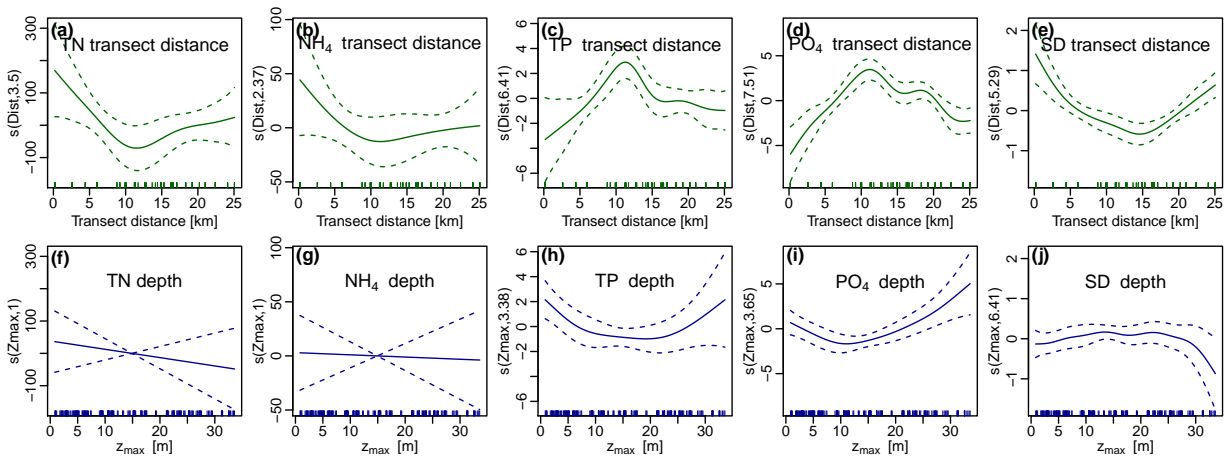

Figure 2: Patterns of important environmental variables (a-e); (TN: total nitrogen; $\mathrm{NH}_{4}$ : ammonia; TP: total phosphorus;

$\mathrm{PO}_{4},:$ soluble phosphorus; $\mathrm{SD}$ : Secchi Disk depth, respectively) demonstrating the horizontal variability and trend along a transect line (thalweg) from the west dam to the south dam in the reservoir; and the variation over depth (0-30 $\mathrm{m})$ for these same variables (f-j). in Miyun Reservoir. 


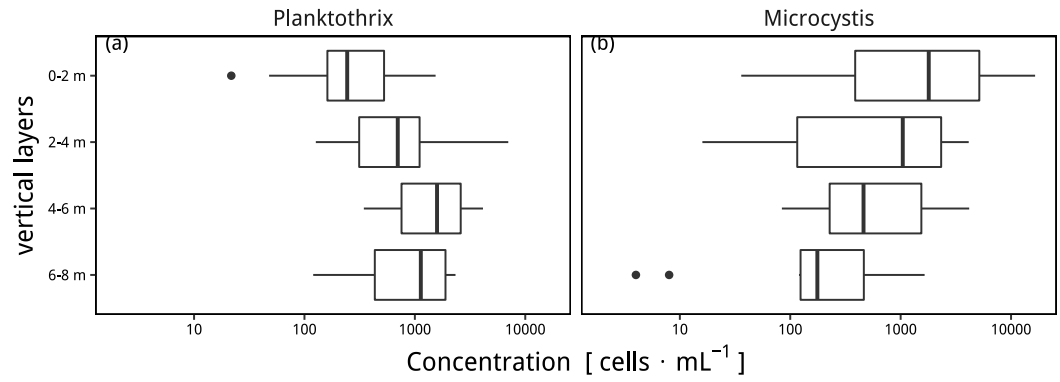

Figure 3: Vertical profile of cell numbers of Microcystis (a) and Planktothrix (b) in the north shallow area (NSR, see Figure A1) during September, 2012, when the 2-MIB concentrations are usually high. (samples were collected on Sep. 7 and 23; sampling time: 10:00-12:00). 


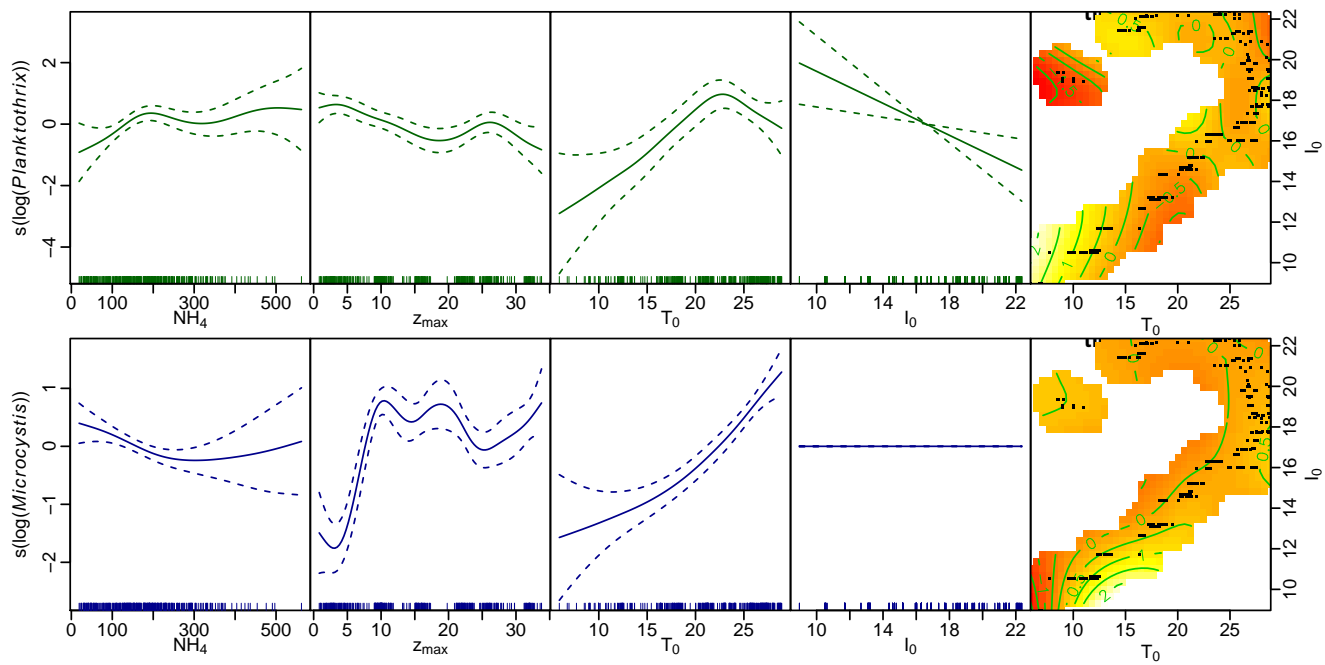

Figure 4: Environmental effect size curves for important growth controlling variables from GAMs fitted to the cell density of Planktothrix (upper) and Microcystis (lower) in the Miyun Reservoir (-), with $95 \%$ confidence bands (- - -). The Y-axis of the 8 figures (on the left) represent 4 environmental effect sizes of ammonia, $\mathrm{z}_{\max }, \mathrm{T}_{0}$ and $\mathrm{I}_{0}$ for both strains, while the 2 figures on the far right are the effect sizes (present by contour lines) of interactions between $\mathrm{I}_{0}$ (Y-axis) and $\mathrm{T}_{0}(\mathrm{X}$-axis)on the two strains. 

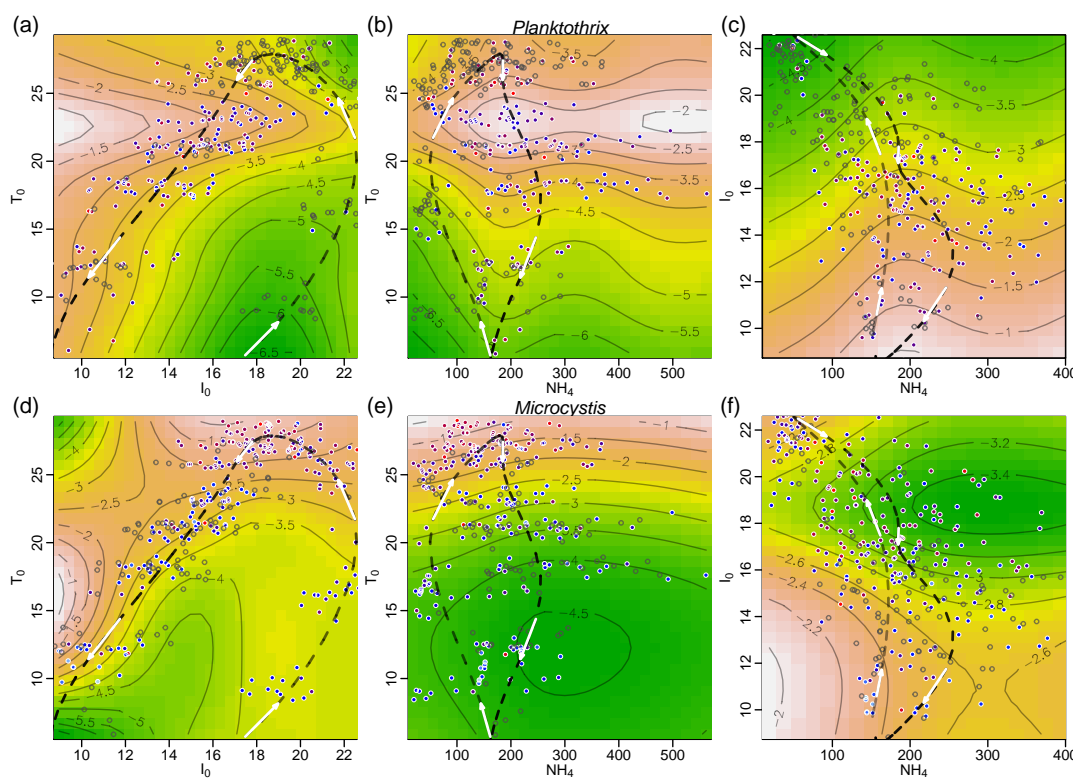

Jan Feb Mar Apr May Jun Jul Aug Sep Oct Nov Dec

Figure 5: Niche analysis of Planktothrix (a-c) and Microcystis (d-f) in relationship to seasonally fluctuating environmental variables in the Miyun Reservoir. The contour colours and lines indicate the predicted logarithms of cell densities in the two genera (from low to high represented by green to bright orange); empty grey circles indicate absence, while white circles indicate presence; blue to dark red colour filled within white circles indicate observed cell density (from low to high); the gray - black lines indicate the long-term and seasonal (January to December) trajectories of the same environmental factors. 

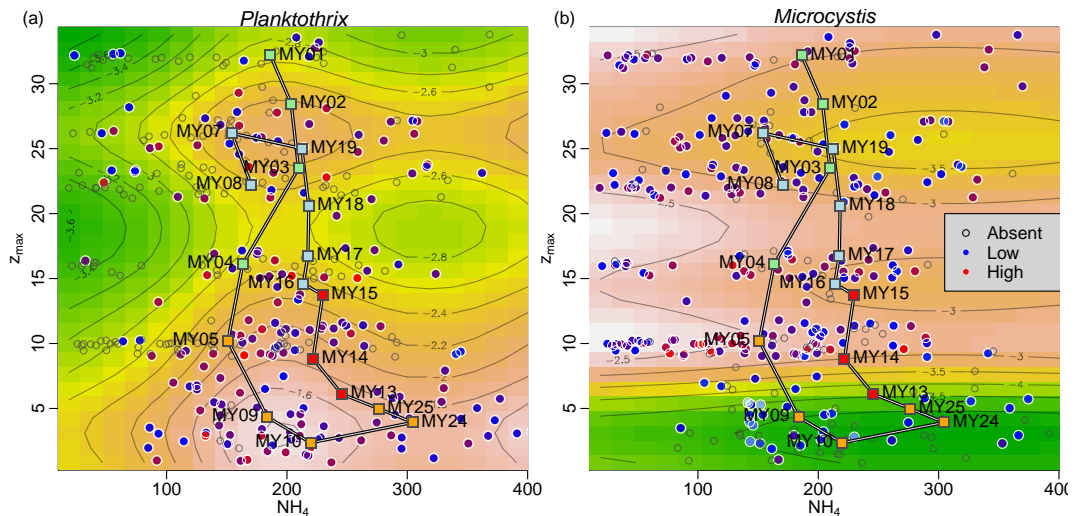

Figure 6: Miyun Reservoir niche analysis of Planktothrix sp. (a) and Microcystis spp. (b) on spatially varied factors $\left(\mathrm{NH}_{4}\right.$ and $z_{\max }$ ) for average September conditions. The contour colour, lines, and circles represent the same as in Figure 5; the squares filled by four colours indicate the sampling sites in four regions: west reservoir region (green); north reservoir region (yellow); northeast reservoir region (red); south reservoir region (light blue). Detailed information can be found in Figure A1. 


\section{$599 \quad$ List of Tables}

$600 \quad 1$ Significance of each predictor of Planktothrix and Microcystis in GAMs . . . . . 28

2 Growth potential of surface and subsurface cyanobacteria . . . . . . . . . . . . . 29 
Table 1: Significance of each predictor of Planktothrix and Microcystis in GAMs

\begin{tabular}{|c|c|c|c|c|c|c|}
\hline \multirow{2}{*}{$\begin{array}{l}\text { Smooth } \\
\text { terms }\end{array}$} & \multicolumn{3}{|c|}{ Planktothrix } & \multicolumn{3}{|c|}{ Microcystis } \\
\hline & $\mathrm{F}$ & p-value & sig. $^{a}$ & $\mathrm{~F}$ & p-value & sig. \\
\hline $\mathrm{s}(\mathrm{TN})$ & 0.000 & 0.750 & \multirow{4}{*}{ ** } & 0.000 & 0.942 & \multirow{4}{*}{ ** } \\
\hline $\mathrm{s}\left(\mathrm{NH}_{4}\right)$ & 1.298 & 0.008 & & 1.056 & 0.002 & \\
\hline $\mathrm{s}(\mathrm{TP})$ & 0.000 & 0.405 & & 0.061 & 0.206 & \\
\hline $\mathrm{s}(\mathrm{SD})$ & 0.000 & 0.430 & & 0.000 & 0.409 & \\
\hline $\mathrm{s}\left(\mathrm{z}_{\max }\right)$ & 2.298 & $<0.001$ & \multirow{2}{*}{$\begin{array}{l}* * * \\
* * *\end{array}$} & 10.307 & $<0.001$ & *** \\
\hline $\mathrm{s}\left(\mathrm{T}_{0}\right)$ & 6.990 & $<0.001$ & & 7.122 & $<0.001$ & \multirow[t]{2}{*}{$* * *$} \\
\hline $\mathrm{s}\left(\mathrm{I}_{0}\right)$ & 1.336 & $<0.001$ & \multirow{2}{*}{ *** } & 0.000 & 0.249 & \\
\hline $\operatorname{ti}\left(\mathrm{T}_{0}, \mathrm{I}_{0}\right)$ & 0.238 & 0.060 & & 1.095 & 0.003 & $* *$ \\
\hline Summary & \multicolumn{3}{|c|}{$0.268,38.1 \%^{\mathrm{c}}$} & \multicolumn{3}{|c|}{$0.458, \quad 51.0 \%$} \\
\hline
\end{tabular}

$\mathrm{a} * * *:<0.001, * *:<0.01, .:<0.1 \quad{ }^{\mathrm{b}}$ R-sq.(adj)

${ }^{\mathrm{c}}$ Deviance explained percentage. 
Table 2: Growth potential of surface and subsurface cyanobacteria

\begin{tabular}{|c|c|c|c|c|c|c|c|}
\hline \multirow{2}{*}{$\begin{array}{l}\text { Light } \\
\text { irradiance }^{\mathrm{a}}\end{array}$} & \multirow{2}{*}{$\begin{array}{l}\text { Water } \\
\text { depth }^{\text {b }}\end{array}$} & \multicolumn{2}{|c|}{ Oligo- } & \multicolumn{2}{|c|}{ Meso- } & \multicolumn{2}{|c|}{ Eutrophic } \\
\hline & & SLC $^{\mathrm{C}}$ & $\mathrm{SSC}^{\mathrm{d}}$ & SLC & SSC & SLC & $\mathrm{SSC}$ \\
\hline \multirow{3}{*}{ High } & Shallow & $* * \mathrm{e}$ & * & $* * * *$ & * & $* * * * *$ & \\
\hline & Median & $*$ & * & $* * *$ & $* *$ & $* * * *$ & * \\
\hline & Deep & $*$ & & $* *$ & * & $* * *$ & $* *$ \\
\hline \multirow{3}{*}{ Median } & Shallow & $*$ & $* *$ & $* * *$ & $* *$ & $* * * *$ & * \\
\hline & Median & $*$ & * & $* *$ & $* *$ & $* *$ & $* *$ \\
\hline & Deep & & & * & * & * & $* *$ \\
\hline
\end{tabular}

a: High "light" represent relatively strong light irradiance such as in summer, median values represent lower light irradiance such as in autumn or spring; while low light irradiance is not included since both surface and subsurface cyanobacterial blooms are rarely recorded;

b: The water depth defined as deep represent the stratification may occur in the water column dur-

ing summer, while shallow represent no stratification occurs.

c: SLC, surface-living cyanobacteria; d: SSC, subsurface cyanobacteria;

e: growth potential, *****: very high, *: low; empty: very low. 